\title{
Selection of optimal variant route based on dynamic fuzzy GRA
}

\author{
Jalil Heidary Dahooie ${ }^{a}$, Amir Salar Vanaki ${ }^{b}$, Navid Mohammadi ${ }^{c^{*}}$ and Hamid Reza Firoozfar ${ }^{\mathrm{d}}$
}

${ }^{a}$ Assistant professor, faculty of management, university of Tehran, Tehran, Iran

${ }^{b}$ Master of business administrator, faculty of management, university of Tehran, Tehran, Iran

${ }^{c}$ Master of management of technology, faculty of management, university of Tehran, Tehran, Iran

${ }^{d}$ Master of business administrator, faculty of management, university of Tehran, Tehran, Iran

\section{H R O N I C L E}

Article history:

Received March 2, 2017

Received in revised format:

October 20, 2017

Accepted November 28, 2017

Available online

November 28, 2017

Keywords:

Variant route

Isfahan-Shiraz freeway

$M A D M$

Dynamic fuzzy GRA

\section{A B S T R A C T}

Given the high costs of construction and maintenance, an optimum design methodology is one of the most important steps towards the development of transportation infrastructure, especially freeways. However, the effects of different variables on the decision-making process to find an optimal variant have caused the choice to become a very difficult and professional task for decision makers. So, the current paper aims to determine the optimal variant route for IsfahanShiraz freeway through MADM approaches. First, evaluation indices for an optimal route variant are derived through literature review and expert panel assessment. Then, a dynamic fuzzy GRA method is used for weightings and optimal route selection. Bases on the results, the road longevity, views of NGOs and route integration are identified as the highest-weighted criteria in route variant prioritization. Further, Route 3 is defined as the priority for the optimal variant for Isfahan-Shiraz freeway, which is the main basis in practice.

(C) 2018 Growing Science Ltd. All rights reserved.

\section{Introduction}

Making important decisions in today's world requires a regulatory framework, and the use of multiple attribute decision making (MADM) techniques is a good way to develop such framework. With respect to work settings, decision making techniques often help to establish and design new processes, create new variables, and remove conflicts between organizational objectives. Decision making techniques are applied, among others, in civil engineering for the topics related to construction and implementation of new freeways (Brauers et al., 2008a,b). Because of relatively high costs of highway construction and maintenance, the design phase is of great importance (Yakar \& Celik, 2014). Prioritizing investment plans in transportation infrastructure projects is a matter of common concern in transportation policies at all levels. Hence, it seems necessary to provide a clear decision-making methodology in order to determine the optimal and the best possible route and/or the most adequate transportation techniques (Gühnemann et al., 2012).

* Corresponding author. Tel.: +982188000245

E-mail address: navid.m@ut.ac.ir (N. Mohammadi)

2018 Growing Science Ltd.

doi: $10.5267 /$ j.dsl.2017.11.004 
Major problems related to road construction are great interests across many countries. This importance lies in the effective role that optimal road transport systems play in economic development. Finding the feasible and optimal route requires to consider various dimensions such as economic aspects and road characteristics. However, a great number of people deal with the issues relevant to the process of road and freeway construction and maintenance every day, and such an important feature also adds significant contributions to this field. Before initiating construction activities, therefore, it is essential to determine environmental impacts during the design phase, as to fully meet resource requirements of road building (Geneletti, 2005). Since the choice of optimal variant route is complex and difficult; the use of MADM techniques will help assessing this process in different situations based on different indicators, thereby facilitating the selection. This type of decision making can be very useful, while the analysis of decision alternatives depends on a wide variety of parameters (De Luca et al., 2012; de Silva $\&$ Tatam, 1996; Kalamaras et al., 2000). The application of MADM methods deals with both qualitative and quantitative indices (Haghighat, 2011).

The purpose of this study is to determine the optimal variant route among a set of several variants for Isfahan - Shiraz freeway. To this end, the four existing variants of the freeway route are selected and analyzed. The proposed routes are located within the Beyza in the Kamfiruz plains (Fars, Iran). As the approved plan from the Ministry of Roads and Urban Development, the primary route has been selected by Pars Consulting Engineers Group. Other three candidates have been proposed by Omran Tadbir Kooshan Consulting Engineers. Novel MADM approaches are used for the assessment and selection of optimal route. In order to develop the evaluation framework for research indices, a variety of studies are reviewed and the preliminary list of indicators are derived. Then, several meetings of expert panel on the road construction and urban development are held and the major indices in terms of frequency and significance informed by the experts are determined as the final indicators. A total of 35 indicators are selected for the choice of optimal variant route. Based on expert opinions and using dynamic fuzzy GRA method, each indicator is weighted and, finally, the optimal variant of the route is determined from the four candidates.

At the following, a review of literature is conducted and the preliminary list of evaluation criteria for optimal route variants is presented. Next, the methodology of dynamic fuzzy GRA is described. When the sample case study is introduced, criteria weighting and the optimal route selection are provided for the route variants. Finally, the main results are concluded, and some recommendations are proposed for future studies.

\section{Literature Review}

Given the high costs of construction and maintenance, the design, construction and operational phases of urban and metropolitan roads are of great importance (Yakar \& Celik, 2014). As stated in the literature, the choice of optimal variant route is a really tough decision in the field of road construction. Making sound decisions needs to pay attention to various aspects and effective indicators (Geneletti, 2005) and the application of MADM techniques can meet this demand. Taking into account a variety of problem dimensions and decision-making indices will lead to achievement of the most optimal and the best possible choices. The following provides a discussion on a range of research studies in the area of the best route selection and indicator extraction for evaluations.

Guzolek and Koch (1989) assessed real-time route planning to determine the best selection in road networks. The authors used six optimization criteria including; speed limits, distance, time of day traffic conditions, traffic signal and stop sign delays, type of surface, and turning delays at an intersection. Price (1999) proposed an approach for the appraisal of road projects in England. In this regard, five major categories of evaluation criteria were applied, namely; environmental impact, safety, economy, accessibility, and integration, with 15 sub-criteria. Dealing with a cost-based assessment for the impacts of climate change in the polar region, Atkinson et al. (2005) provided an MADM problem with nine categories. Zhang (2005) developed a new framework for road network extraction based on a 
connection analysis. This study focused on criteria for road conditions that affect the decision making process specific to road networks. Cantarella and Vitetta (2006) presented a multi-objective programming model using the genetic algorithm approach for urban network design. Four major criteria under investigation included travel time, travel congestion, budget for investments, and pollutant emissions. Russo and Vitetta (2006) proposed a topological method for the classification and selection of optimal solutions for an urban road network design problem. The methodology utilized three viewpoints of customer, management and process. Using the MOORA method, Brauers et al. (2008a) addressed decision making models for the choice of the best road design alternative. A predetermined number of six route variants were selected, and the evaluation indicators consisted of longevity, construction price, environmental protection, economic validity, and construction duration. Yavuz et al. (2008) presented an optimum support design selection by using Analytical Hierarchy Process (AHP) (Saaty, 1998) method for the main haulage road in WLC Tuncbilek colliery. The authors applied eight major criteria against which nine alternatives were evaluated. Abdi et al. (2009) utilized a hybrid MADM method with geographic information system (GIS) to design a forest road network with minimum total construction costs. The decision making analysis identified six factors as being relevant to the costs of forest roads. Beljatynskij et al. (2009) examined major criteria required for the objective of highway reconstruction. In this paper, Ukraine was evaluated as the sample case study based on the theory of traffic flows and repay time. Gühnemann et al. (2012) proposed a hybrid approach for MADM and cost-benefit analysis to prioritize Ireland's national road infrastructure programe. Xiaowei (2013) dealt with the highway network planning, using a MADM approach with five categories for evaluation indices. Jato-Espino et al. (2014) investigated the application of MADM techniques in the construction industry. This review used different methods for comparative analyses. Gardziejczyk and Zabicki (2014) studied the influences of scenario and assessment method on the choice of the best possible route variant. The authors identified a total of 11 criteria with significant impacts on the optimal variant selection. Nosal and Solecka (2014) provided an AHP ranking method for finding the best route variant in an urban transportation network. The criteria composed of travel time, journey standard, rolling stock use index, environmentally friendly, level of integration of public urban transport system, reliability of urban public transport system, safety of journeys, profitability of the urban public transport system, availability of the urban public transport system, and investment costs. Using MADM approaches in combination with GIS, Yakar and Celik (2014) proposed a highway alignment determination model. Six main categories of general criteria and 26 indices were used for the assessment. The selection criteria included economic, engineering, traffic, environmental, social and land use criteria.

Table 1

Evaluation Criteria for Optimal Route Variant

\begin{tabular}{llll}
\hline No. & Criteria & No. & Criteria \\
\hline C1 & Economic cost & C19 & Pedestrian and harmony \\
C2 & Tourism development & C20 & Total time spent on the tracking \\
C3 & Commerce and Industry, and ease of & C21 & Total time taken to change the chain \\
C4 & Transport cost & C22 & Prevent contact with water \\
C5 & Accident costs & C23 & Air and water pollution \\
C6 & Investment funds & C24 & Erosion \\
C7 & Road longevity & C25 & Noise \\
C8 & topographic features & C26 & Avoidance of forest resources \\
C9 & Geologic features & C27 & Avoidance of wildlife \\
C10 & Structural safety & C28 & Soil contamination \\
C11 & Climate characteristics & C29 & Close to stone resources \\
C12 & Road conditions & C30 & Avoidance of cultural locations \\
C13 & Highway network conditions & C31 & Resettlement \\
C14 & Ease of tracking & C32 & Public activities \\
C15 & Integration & C33 & Public views \\
C16 & Minimized traffic flow & C34 & Views of NGOs \\
C17 & Traffic safety & C35 & Conflict resolution \\
C18 & Accessibility & & \\
\hline
\end{tabular}


Through a review of studies about the optimal route selection and extracting of evaluation indicators, the basic framework is achieved. Then, the meetings of expert panel on the road construction and urban development are held as to finalize indicators and develop the alternative assessment framework using new MADM techniques. Table 1 shows the criteria against which the alternatives are assessed. The evaluation criteria are classified into 35 basic categories.

\section{Material and methods}

This study aims to find the optimal variant route for Isfahan - Shiraz freeway. To this end, the four predetermined variants of the freeway route are selected and analyzed. As stated, the proposed routs are located within the Beyza in the Kamfiruz plains (Fars, Iran). As the approved plan from the Ministry of Roads and Urban Development, the primary route has been selected by Pars Consulting Engineers Group. Other three candidates have been proposed by Omran Tadbir Kooshan Consulting Engineers. The research methodology covers five basic stages as the following. First, a review of literature in the field of optimal variant selection is presented. Then, a set of indicators necessary for decision making is derived and integrated. The indicators are finalized through expert panel discussions, attended by Construction and Development of Transportation Infrastructures Company (of the Ministry of Roads and Urban Construction), Isfahan-Shiraz Freeway Company, Omran Tadbir Kooshan Consulting Engineers, Faradid Consulting Engineers, Polrood Consulting Engineers, Iran Building and Road Construction Company, and Pars Gostar Company. Stage 4 includes the application of the six-step dynamic fuzzy GRA method to determine criteria weights, provided in details below. The last step produces final scores for each alternative and, ultimately, the route with the highest ranking score is defined as the optimal variant for Isfahan - Shiraz freeway, using the dynamic intuitionistic fuzzy GRA method with interval numbers. Fig. 1 shows the flowchart of the procedure used in this paper.

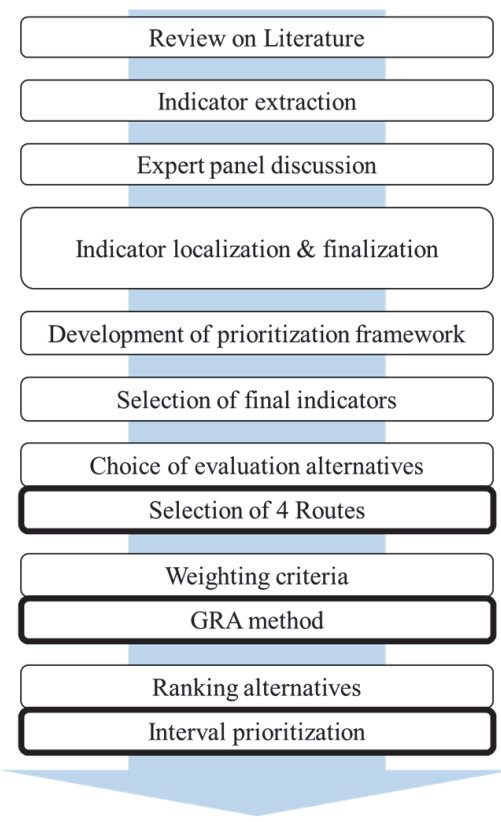

Fig. 1. Research Methodology

\subsection{Dynamic Fuzzy GRA}

For this study, criteria values are regarded as linguistic values of the linguistic variables. The linguistic variables can be described as interval-valued triangular fuzzy numbers, which better demonstrate the complexity of real situations. The scale measurement of interval-valued triangular fuzzy numbers is determined based on the uncertainty and ambiguity existing in decision-making problems (Zhang et al., 2011). A scale of seven-point triangular fuzzy numbers is used here, as seen in Table 2. 
Like MADM problems, suppose a finite set of alternatives (A), $A=\left\{A_{1}, A_{2}, \ldots, A_{m}\right\}$; a finite set of criteria (C), $C=\left\{C_{1}, C_{2}, \ldots, C_{n}\right\}$; and a criteria weight vector (w), $w=w_{1}, w_{2}, \ldots, w_{n}$ are the problem assumptions. The weight vector of the criteria satisfies $w_{j} \geq 0,=1,2, \ldots, n$; and $\sum_{j=1}^{n} w_{j}=1$. In addition, the performance of the alternative $A_{i}$ with respect to the criterion $C_{j}$ is denoted as $\tilde{x}_{i j}$.

Table 2

Linguistic Variables for Rankings

\begin{tabular}{ll}
\hline Linguistic variables & Interval-valued triangular fuzzy numbers \\
\hline Very poor $(\mathrm{VP})$ & {$[(0,0.5) ; 0.5 ;(1,1.5)]$} \\
Poor $(\mathrm{P})$ & {$[(0.5,0.5) ; 1 ;(2.5,3.5)]$} \\
Medium poor $(\mathrm{MP})$ & {$[(0.5,1.5) ; 3 ;(4.5,5.5)]$} \\
Medium $(\mathrm{M})$ & {$[(2.5,3.5) ; 5 ;(6.5,7.5)]$} \\
Medium good $(\mathrm{MG})$ & {$[(4.5,5.5) ; 7 ;(8.5,9.5)]$} \\
Good $(\mathrm{G})$ & {$[(5.5,7.5) ; 9 ;(9.5,10)]$} \\
Very good $(\mathrm{VG})$ & {$[(8.5,9.5) ; 10 ;(10,10)]$} \\
\hline
\end{tabular}

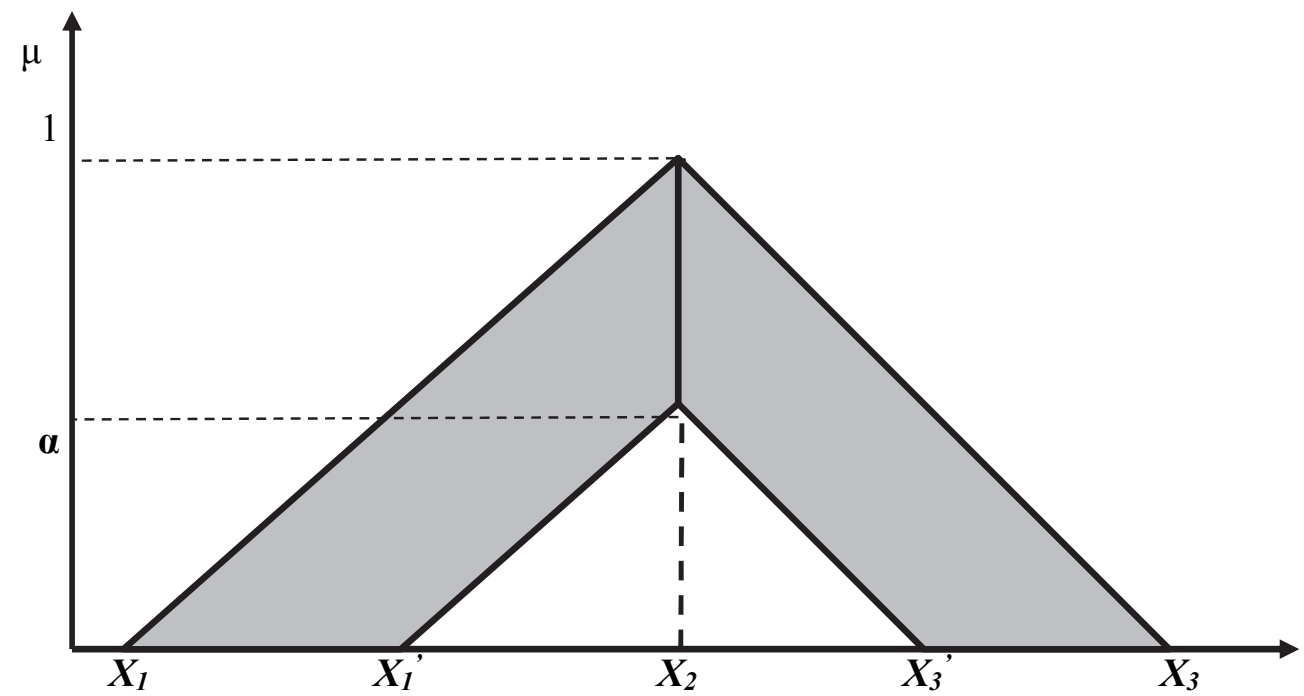

Fig. 2. An Interval-valued Triangular Fuzzy Number

Then, $\tilde{X}=\left[\tilde{x}_{i j}\right]_{m \times n}$ reflects a fuzzy decision matrix. As seen in Fig. 1, $\tilde{x}_{i j}$ represents an interval-valued triangular fuzzy number:

$$
\tilde{x}=\left\{\begin{array}{l}
\left(x_{1}, x_{2}, x_{3}\right) \\
\left(x_{1}^{\prime}, x_{2}, x_{3}^{\prime}\right)
\end{array}\right.
$$

where, $\tilde{x}$ can be also expressed as $\tilde{x}=\left[\left(x_{1}, x_{1}^{\prime}\right) ; x_{2} ;\left(x_{3}^{\prime}, x_{3}\right)\right]$. Below is a brief definition of a dynamic operator.

Definition: $\tilde{x}_{i j}^{\left(t_{k}\right)}=\left\lfloor\tilde{x}_{i j_{1}}{ }^{\left(t_{k}\right)}, \tilde{x}_{i j_{2}}{ }^{\left(t_{k}\right)}, \tilde{x}_{i j_{3}}{ }^{\left(t_{k}\right)}\right\rfloor$ indicates the triangular fuzzy numbers in $p$ periods of $t_{k}$, $k=1,2, \ldots, p$. And, $v(t)=\left(v\left(t_{1}\right), v\left(t_{2}\right), \ldots, v\left(t_{k}\right)\right)$ is the vector of time-weights in the period series $t_{k}, k=1,2, \ldots, p$. Using $\sum_{k=1}^{p} v\left(t_{k}\right)=1$ and $\mathrm{v}\left(t_{k}\right)>0$, the operator can be defined as follows:

$$
\operatorname{DTFWA}_{v_{(t)}}\left(\tilde{x}^{\left(t_{1}\right)}, \tilde{x}^{\left(t_{2}\right)}, \ldots, \tilde{x}^{\left(t_{p}\right)}\right)=\sum_{k=1}^{p} v\left(t_{k}\right) \tilde{x}^{\left(t_{k}\right)}=\left[\sum_{k=1}^{p} v\left(t_{k}\right) x_{1}{ }^{\left(t_{k}\right)}, \sum_{k=1}^{p} v\left(t_{k}\right) x_{2}\left(t_{k}\right), \sum_{k=1}^{p} v\left(t_{k}\right) x_{3}{ }^{\left(t_{k}\right)}\right]
$$

This is called the dynamic triangular fuzzy weighted average (DTFWA) operator. Now, the steps taken for a dynamic GRA method based on interval-valued triangular fuzzy assessment is described as follows. 
Step 1: Assemble Synthetically Interval-valued Triangular Fuzzy Decision Matrix

The interval-valued triangular fuzzy decision matrix $\tilde{X}\left(t_{k}\right)=\left(\tilde{x}_{i j}^{\left(t_{k}\right)}\right)_{m \times n}, k=1,2, \ldots, p$, of each period is integrated into a synthetically interval-valued triangular fuzzy decision matrix, based on the DITFWA operator. The product is demonstrated as $\tilde{X}=\left(\tilde{x}_{i j}\right)_{m \times n}$. And,

$\tilde{x}_{i j}\left(t_{k}\right)=\left[\left(a_{i j}\left(t_{k}\right), a_{i j}^{\prime}\left(t_{k}\right)\right), b_{i j}\left(t_{k}\right),\left(c_{i j}^{\prime}\left(t_{k}\right), c_{i j}\left(t_{k}\right)\right)\right] ;$

$\tilde{x}_{i j}=\left[\left(a_{i j}, a_{i j}^{\prime}\right), b_{i j},\left(c_{i j}^{\prime}, c_{i j}\right)\right] i=1,2, \ldots, m ; j=1,2, \ldots, n$.

Step 2: Calculate Normalized Decision Matrix $\tilde{R}$

According to the definition of $\tilde{x}_{i j}=\left[\left(a_{i j}, a_{i j}^{\prime}\right), b_{i j},\left(c_{i j}^{\prime}, c_{i j}\right)\right]$, the normalized performance ranking can be given as:

$$
\begin{aligned}
& \tilde{r}_{i j}=\left[\left(\frac{a_{i j}}{c_{j}^{+}}, \frac{a_{i j}^{\prime}}{c_{j}^{+}}\right) ; \frac{b_{i j}}{c_{j}^{+}} ;\left(\frac{c_{i j}^{\prime}}{c_{j}^{+}}, \frac{c_{i j}}{c_{j}^{+}}\right)\right], i=1,2, \ldots, m ; j=1,2, \ldots, n, \text { for } j \in I \\
& \tilde{r}_{i j}=\left[\left(\frac{a_{j}^{-}}{c_{i j}}, \frac{a_{j}^{-}}{c_{i j}^{\prime}}\right) ; \frac{a_{j}^{-}}{b_{i j}} ;\left(\frac{a_{j}^{-}}{a_{i j}^{\prime}}, \frac{a_{j}^{-}}{a_{i j}}\right)\right], i=1,2, \ldots, m ; j=1,2, \ldots, n, \text { for } j \in J
\end{aligned}
$$

where, $I$ is the set of benefit criteria, $J$ is the set of cost criteria, $c_{j}^{+}=\max _{i}\left\{c_{i j}, i=1,2, \ldots, m\right\}$, and $a_{j}^{-}=$ $\min _{i}\left\{a_{i j}, i=1,2, \ldots, m\right\}$. Thus, the vector $\tilde{r}_{i j}=\left[\left(g_{i j}, g_{i j}^{\prime}\right) ; h_{i j} ;\left(l_{i j}, l_{i j}^{\prime}\right)\right]$ and also the normalized decision matrix, represented as $\tilde{R}=\left[\tilde{r}_{i j}\right]_{m \times n}$, can be calculated.

Step 3: Determine Reference Series

According to Kuo et al. (2011), the reference series can be expressed as below:

$$
R_{0}=\left(r_{01}, r_{02}, \ldots, r_{0 n}\right)=\left(\begin{array}{c}
{[(1,1) ; 1 ;(1,1)],[(1,1) ; 1 ;(1,1)],} \\
\ldots,[(1,1) ; 1 ;(1,1)]
\end{array}\right)
$$

Step 4: Calculate Distances between Reference Value \& Comparison Values

The distance between the reference value and each comparison value is obtained as:

$$
\begin{aligned}
& \delta_{i j}^{(1)}=\sqrt{\frac{1}{3}\left[\left(g_{i j}^{\prime}-1\right)^{2}+\left(h_{i j}-1\right)^{2}+\left(l_{i j}^{\prime}-1\right)^{2}\right]}, \\
& \delta_{i j}^{(2)}=\sqrt{\frac{1}{3}\left[\left(g_{i j}-1\right)^{2}+\left(h_{i j}-1\right)^{2}+\left(l_{i j}-1\right)^{2}\right]} .
\end{aligned}
$$

Eq. (5) is used to determine the distance between the reference value and comparison values on the interval $\left[\delta_{i j}^{(1)}, \delta_{i j}^{(2)}\right]$. Therefore, the maximum and minimum values can be calculated as follows, represented as $\delta_{\max }^{(1)}$ and $\delta_{\max }^{(2)}$, and $\delta_{\min }^{(1)}$ and $\delta_{\min }^{(2)}$, respectively:

$$
\begin{aligned}
& \delta_{\max }^{(1)}=\max _{i, j} \delta_{i j}^{(1)}, \delta_{\min }^{(1)}=\min _{i, j} \delta_{i j}^{(1)} \\
& \delta_{\max }^{(2)}=\max _{i, j} \delta_{i j}^{(2)}, \delta_{\min }^{(2)}=\min _{i, j} \delta_{i j}^{(2)} \\
& i=1,2, \ldots, m, j=1,2, \ldots, n
\end{aligned}
$$


Step 5: Calculate Grey Relational Coefficients

The grey relational coefficient can be obtained as follows (Wang et al., 2013; Wei, 2010):

$$
\begin{aligned}
& \xi_{i j}^{(1)}=\frac{\delta_{\min }^{(1)}+\zeta \delta_{\max }^{(1)}}{\delta_{i j}^{(1)}+\zeta \delta_{\max }^{(1)}} \\
& \xi_{i j}^{(2)}=\frac{\delta_{\min }^{(2)}+\zeta \delta_{\max }^{(2)}}{\delta_{i j}^{(2)}+\zeta \delta_{\max }^{(2)}}
\end{aligned} \quad i=1,2, \ldots, m, j=1,2, \ldots, n
$$

Note that $\zeta$ is supposed to be 0.5 .

Step 6: Estimate Grey Relational Grade

The grey relational grade is given using Eq. (7):

$$
\begin{aligned}
\gamma_{i}^{(1)} & =\sum_{j=1}^{n} w_{j} \xi_{i j}^{(1)} \\
\gamma_{i}^{(2)} & =\sum_{j=1}^{n} w_{j} \xi_{i j}^{(2)}
\end{aligned} i=1,2, \ldots, m
$$

Based on the basic principle of the GRA method, the chosen alternative should have the highest grey relation grade from the reference solution (Wei, 2010). Also, the weight information can be obtained as follows (Zhang et al., 2011):

$$
w_{j}=\frac{\sum_{i=1}^{m}\left(\xi_{i j}^{(1)}+\xi_{i j}^{(2)}\right)}{\sum_{i=1}^{m} \sum_{j=1}^{n}\left(\xi_{i j}^{(1)}+\xi_{i j}^{(2)}\right)}
$$

The weight vector of criteria, $\mathrm{w}$, is defined as $w=\left(w_{1}, w_{2}, \ldots, w_{n}\right)$. Then, $\gamma_{i}^{(1)}$ and $\gamma_{i}^{(2)}$ are expressed using Eq. (7).

\section{Step 7: Rank Alternatives}

The priority of the alternative $A_{s}$ over the alternative $A_{t}$ is shown by $A_{s} \geq A_{t}$. The likelihood of $A_{s} \geq$ $A_{t}$ is measured based on the relation $\bar{\gamma}_{s} \geq \bar{\gamma}_{t}$. Here, $\bar{\gamma}_{s}$ and $\bar{\gamma}_{t}$ correspond the grey relational grades of the interval numbers for the alternatives $A_{s}$ and $A_{t}$ in $A$. According to the concept of likelihood for interval numbers (Li et al., 2009), the likelihood of $A_{s} \geq A_{t}$ for two alternatives of $A_{s}$ and $A_{t}$ in $A$ is determined as follows:

$$
p\left(A_{s} \geq A_{t}\right)=p\left(\bar{\gamma}_{s} \geq \bar{\gamma}_{t}\right)=\max \left\{1-\max \left\{\frac{\gamma_{t}^{(2)}-\gamma_{s}^{(1)}}{L\left(\bar{\gamma}_{s}\right)+L\left(\bar{\gamma}_{t}\right)}, 0\right\}, 0\right\}
$$

where $\bar{\gamma}_{s}=\left[\gamma_{s}^{(1)}, \gamma_{s}^{(2)}\right], \bar{\gamma}_{t}=\left[\gamma_{t}^{(1)}, \gamma_{t}^{(2)}\right], L\left(\bar{\gamma}_{s}\right)=\gamma_{s}^{(2)}-\gamma_{s}^{(1)}, L\left(\bar{\gamma}_{t}\right)=\gamma_{t}^{(2)}-\gamma_{t}^{(1)}$

Thus, the likelihood matrix can be given using Eq. (10):

$$
P=\left(p_{s t}\right)_{m \times m}=\left[\begin{array}{cccc}
p_{11} & p_{12} & \cdots & p_{1 m} \\
p_{21} & p_{22} & \cdots & p_{2 m} \\
\vdots & \vdots & & \vdots \\
p_{m 1} & p_{m 2} & \cdots & p_{m m}
\end{array}\right]
$$

where $p_{s t}=p\left(A_{s} \geq A_{t}\right)(s, t=1,2, \ldots, m)$ holds for the alternatives $A_{s}$ and $A_{t}$ in $A$.

Since the matrix $\mathrm{P}$ is a fuzzy complementary judgment matrix, the optimal degree of membership for the alternative $A_{i}, i=1,2, \ldots, m$, is defined as below:

$$
V_{i}=\frac{1}{m(m-1)}\left(\sum_{r=1}^{m} p_{i r}+\frac{m}{2}-1\right) .
$$


Therefore, the sort vector of $V=\left(V_{1}, V_{2}, \ldots, V_{m}\right)$ for the alternatives can be obtained.

Now, the alternatives all will be ranked in accordance with $V_{i}(i=1,2, \ldots, m)$. The larger the value of $V_{i}$, the better the alternative $A_{i}$ is.

\subsection{Case Study}

As a case study, the research takes a look at the construction project of Isfahan-Shiraz freeway. This route can shorten the current travel distance between two cities by $113 \mathrm{~km}$. From the long-term perspective, it is hoped that by linking Shiraz- Bushehr freeway (under investigation), this freeway will form part of the country's North-South Transport Corridor, building a freeway network. Isfahan- Shiraz freeway covers 210 kilometers, consisting of 7 segments. It begins at KM $624+116$ at a distance of approximately $8 \mathrm{~km}$ from the city of Izad-Khast, and continues north almost all the way until the north of Shiraz. The freeway passes close to the rural areas of Izad-khast, Khosro Shirin, Chahar Dare, Yasouj (located around $50 \mathrm{~km}$ away), Tang-e Boraq, Mollasadra Dam, Margon waterfall, Behesht-e Gomshodeh, and Kamfirroz. It also passes through the fertile land of Kor River, and stretches to the Beyza plain. Finally, the freeway ends at the region known as Tang-e Khiareh in north Shiraz at KM $800+325$. As noted before, the starting point of the first segment is Izad-Khast, the central district of Abadeh. It spreads across the eastern slopes of Morvarid Mountain to enter the Sheikh Ahamd Plain. Segment 2 is the crossing of this plain over the Khosrow Shirin rural district of Abadeh. Segment 3 runs along the town of Eghlid, stretching to the junction of Yasouj-Eghlid. Within Segment 4, there are the village of Tang-e Boraq and the fertile soil of Kamfiroz, where rice cultivation is widespread. The route enters the village of Ab Mahi. Segment 5 starts at this point, around which Tang-e Bostanak Protected Area is located and the segment approaches the village of Memo. After crossing Memo, Segment 6 runs to Tang-e Khiareh; however, Segment 7 which continues south to Shiraz is under investigation. As the approved plan from the Ministry of Roads and Urban Development, the primary route has been selected by Pars Consulting Engineers Group, which was described in details in previous section. Other three candidates have been proposed by Omran Tadbir Kooshan Consulting Engineers.

\section{Results \& Discussion}

As stated before, in order to select the optimal route variant, a total of 35 indicators are derived through review of the literature and finalized by a panel of experts. There are four route variants predetermined for Isfahan-Shiraz freeway. As illustrated in Table 2, these variants are investigated against the specified criteria and all 35 criteria and expert evaluations by means of linguistic variables in Table 2 are represented below. The selected criteria are first derived by a review of the literature and research studies, and then finalized through several meetings of expert panel on the road construction and urban development. The finalized criteria are adopted to select the best possible route variant.

Table 3

A Decision Table with Attribute Evaluations based on Expert Opinions

\begin{tabular}{lcccccccccccc}
\hline Criteria & C1 & C2 & C3 & C4 & C5 & C6 & C7 & C8 & C9 & C10 & C11 & C12 \\
\hline Variant path1 & MG & P & MG & M & G & M & VG & M & MG & G & MP & M \\
Variant path2 & MG & P & MG & MP & MG & MP & VG & M & MG & MG & MP & M \\
Variant path3 & G & P & MG & G & MG & G & VG & M & MG & MG & MP & M \\
Variant path4 & M & P & MG & P & M & P & VG & M & MG & M & MP & M \\
\hline Criteria & C13 & C14 & C15 & C16 & C17 & C18 & C19 & C20 & C21 & C22 & C23 & C24 \\
\hline Variant path1 & M & G & G & M & G & MG & M & M & M & M & G & G \\
Variant path2 & M & G & G & M & MG & MG & M & MP & M & M & G & G \\
Variant path3 & M & G & G & M & MG & MG & M & G & M & M & G & G \\
Variant path4 & M & M & MG & M & M & MG & M & P & M & M & G & G \\
\hline Criteria & C25 & C26 & C27 & C28 & C29 & C30 & C31 & C32 & C33 & C34 & C35 & M \\
Variant path1 & P & MP & MP & M & M & M & M & M & P & G & MG & MG \\
Variant path2 & P & MP & MP & M & M & M & M & M & P & G & MG \\
Variant path3 & P & MP & MP & M & M & M & M & M & P & G & G & M \\
Variant path4 & P & MP & MP & M & M & G & M & M & P & G & P &
\end{tabular}


As the linguistic variables are replaced by interval-valued triangular fuzzy numbers in accordance with the calculation in Table 2, the resulting decision matrix can be normalized using Eq. (2) and Eq. (3). Eq. (4) is used to determine the reference series which reflect the reference value of each criterion. However, Eq. (5) calculates the distance from the reference values. Table 4 presents the results.

\section{Table 4}

Calculation of Distance between the Reference Value \& Comparison Values

\begin{tabular}{|c|c|c|c|c|}
\hline Criteria & Variant path1 & Variant path2 & Variant path3 & Variant path4 \\
\hline $\mathrm{C} 1$ & {$[0.601,0.646]$} & {$[0.601,0.646]$} & {$[0.674,0.714]$} & {$[0.458,0.509]$} \\
\hline $\mathrm{C} 2$ & {$[0.644,0.665]$} & {$[0.644,0.665]$} & {$[0.644,0.665]$} & {$[0.644,0.665]$} \\
\hline $\mathrm{C} 3$ & {$[0.287,0.352]$} & {$[0.287,0.352]$} & {$[0.287,0.352]$} & {$[0.287,0.352]$} \\
\hline $\mathrm{C} 4$ & {$[0.876,0.897]$} & {$[0.703,0.809]$} & {$[0.934,0.943]$} & {$[0.545,0.573]$} \\
\hline $\mathrm{C} 5$ & {$[0.674,0.714]$} & {$[0.601,0.646]$} & {$[0.601,0.646]$} & {$[0.458,0.509]$} \\
\hline C6 & {$[0.495,0.558]$} & {$[0.687,0.752]$} & {$[0.155,0.268]$} & {$[0.844,0.871]$} \\
\hline $\mathrm{C} 7$ & {$[0.029,0.087]$} & {$[0.029,0.087]$} & {$[0.029,0.087]$} & {$[0.029,0.087]$} \\
\hline $\mathrm{C} 8$ & {$[0.363,0.437]$} & {$[0.363,0.437]$} & {$[0.363,0.437]$} & {$[0.363,0.437]$} \\
\hline C9 & {$[0.287,0.352]$} & {$[0.287,0.352]$} & {$[0.287,0.352]$} & {$[0.287,0.352]$} \\
\hline $\mathrm{C} 10$ & {$[0.155,0.268]$} & {$[0.314,0.380]$} & {$[0.314,0.380]$} & {$[0.495,0.558]$} \\
\hline $\mathrm{C} 11$ & {$[0.495,0.596]$} & {$[0.495,0.596]$} & {$[0.495,0.596]$} & {$[0.495,0.596]$} \\
\hline $\mathrm{C} 12$ & {$[0.363,0.437]$} & {$[0.363,0.437]$} & {$[0.363,0.437]$} & {$[0.363,0.437]$} \\
\hline $\mathrm{C} 13$ & {$[0.363,0.437]$} & {$[0.363,0.437]$} & {$[0.363,0.437]$} & {$[0.363,0.437]$} \\
\hline $\mathrm{C} 14$ & {$[0.155,0.268]$} & {$[0.155,0.268]$} & {$[0.155,0.268]$} & {$[0.495,0.558]$} \\
\hline $\mathrm{C} 15$ & {$[0.155,0.268]$} & {$[0.155,0.268]$} & {$[0.155,0.268]$} & {$[0.314,0.380]$} \\
\hline $\mathrm{C} 16$ & {$[0.363,0.437]$} & {$[0.363,0.437]$} & {$[0.363,0.437]$} & {$[0.363,0.437]$} \\
\hline $\mathrm{C} 17$ & {$[0.155,0.268]$} & {$[0.314,0.380]$} & {$[0.314,0.380]$} & {$[0.495,0.558]$} \\
\hline $\mathrm{C} 18$ & {$[0.287,0.352]$} & {$[0.287,0.352]$} & {$[0.287,0.352]$} & {$[0.287,0.352]$} \\
\hline C19 & {$[0.363,0.437]$} & {$[0.363,0.437]$} & {$[0.363,0.437]$} & {$[0.363,0.437]$} \\
\hline $\mathrm{C} 20$ & {$[0.876,0.897]$} & {$[0.703,0.809]$} & {$[0.934,0.943]$} & {$[0.545,0.573]$} \\
\hline $\mathrm{C} 21$ & {$[0.458,0.509]$} & {$[0.458,0.509]$} & {$[0.458,0.509]$} & {$[0.458,0.509]$} \\
\hline $\mathrm{C} 22$ & {$[0.363,0.437]$} & {$[0.363,0.437]$} & {$[0.363,0.437]$} & {$[0.363,0.437]$} \\
\hline $\mathrm{C} 23$ & {$[0.331,0.376]$} & {$[0.331,0.376]$} & {$[0.331,0.376]$} & {$[0.331,0.376]$} \\
\hline $\mathrm{C} 24$ & {$[0.331,0.376]$} & {$[0.331,0.376]$} & {$[0.331,0.376]$} & {$[0.331,0.376]$} \\
\hline $\mathrm{C} 25$ & {$[0.545,0.573]$} & {$[0.545,0.573]$} & {$[0.545,0.573]$} & {$[0.545,0.573]$} \\
\hline $\mathrm{C} 26$ & {$[0.495,0.596]$} & {$[0.495,0.596]$} & {$[0.495,0.596]$} & {$[0.495,0.596]$} \\
\hline $\mathrm{C} 27$ & {$[0.495,0.596]$} & {$[0.495,0.596]$} & {$[0.495,0.596]$} & {$[0.495,0.596]$} \\
\hline $\mathrm{C} 28$ & {$[0.458,0.509]$} & {$[0.458,0.509]$} & {$[0.458,0.509]$} & {$[0.458,0.509]$} \\
\hline $\mathrm{C} 29$ & {$[0.363,0.437]$} & {$[0.363,0.437]$} & {$[0.363,0.437]$} & {$[0.363,0.437]$} \\
\hline $\mathrm{C} 30$ & {$[0.495,0.558]$} & {$[0.495,0.558]$} & {$[0.495,0.558]$} & {$[0.155,0.268]$} \\
\hline $\mathrm{C} 31$ & {$[0.458,0.509]$} & {$[0.458,0.509]$} & {$[0.458,0.509]$} & {$[0.458,0.509]$} \\
\hline C32 & {$[0.363,0.437]$} & {$[0.363,0.437]$} & {$[0.363,0.437]$} & {$[0.363,0.437]$} \\
\hline $\mathrm{C} 33$ & {$[0.644,0.665]$} & {$[0.644,0.665]$} & {$[0.644,0.665]$} & {$[0.644,0.665]$} \\
\hline C34 & {$[0.155,0.268]$} & {$[0.155,0.268]$} & {$[0.155,0.268]$} & {$[0.155,0.268]$} \\
\hline C35 & {$[0.314,0.380]$} & {$[0.314,0.380]$} & {$[0.155,0.268]$} & {$[0.844,0.871]$} \\
\hline
\end{tabular}

Based on the values obtained from Table 3, the grey relational coefficients can be derived using Eq. (6). The results are provided in Table 5. 
Table 5

Grey Relational Coefficients

\begin{tabular}{|c|c|c|c|c|}
\hline Criteria & Variant path1 & Variant path2 & Variant path3 & Variant path4 \\
\hline $\mathrm{C} 1$ & {$[0.464,0.499]$} & {$[0.464,0.499]$} & {$[0.435,0.471]$} & {$[0.536,0.569]$} \\
\hline $\mathrm{C} 2$ & {$[0.446,0.491]$} & {$[0.446,0.491]$} & {$[0.446,0.491]$} & {$[0.446,0.491]$} \\
\hline $\mathrm{C} 3$ & {$[0.658,0.678]$} & {$[0.658,0.678]$} & {$[0.658,0.678]$} & {$[0.658,0.678]$} \\
\hline $\mathrm{C} 4$ & {$[0.369,0.408]$} & {$[0.424,0.436]$} & {$[0.354,0.395]$} & {$[0.490,0.534]$} \\
\hline $\mathrm{C} 5$ & {$[0.435,0.471]$} & {$[0.464,0.499]$} & {$[0.464,0.499]$} & {$[0.536,0.569]$} \\
\hline C6 & {$[0.515,0.542]$} & {$[0.430,0.456]$} & {$[0.797,0.755]$} & {$[0.378,0.416]$} \\
\hline $\mathrm{C} 7$ & {$[1.000,1.000]$} & {$[1.000,1.000]$} & {$[1.000,1.000]$} & {$[1.000,1.000]$} \\
\hline $\mathrm{C} 8$ & {$[0.597,0.614]$} & {$[0.597,0.614]$} & {$[0.597,0.614]$} & {$[0.597,0.614]$} \\
\hline C9 & {$[0.658,0.678]$} & {$[0.658,0.678]$} & {$[0.658,0.678]$} & {$[0.658,0.678]$} \\
\hline $\mathrm{C} 10$ & {$[0.797,0.755]$} & {$[0.635,0.656]$} & {$[0.635,0.656]$} & {$[0.515,0.542]$} \\
\hline $\mathrm{C} 11$ & {$[0.515,0.523]$} & {$[0.515,0.523]$} & {$[0.515,0.523]$} & {$[0.515,0.523]$} \\
\hline $\mathrm{C} 12$ & {$[0.597,0.614]$} & {$[0.597,0.614]$} & {$[0.597,0.614]$} & {$[0.597,0.614]$} \\
\hline $\mathrm{C} 13$ & {$[0.597,0.614]$} & {$[0.597,0.614]$} & {$[0.597,0.614]$} & {$[0.597,0.614]$} \\
\hline $\mathrm{C} 14$ & {$[0.797,0.755]$} & {$[0.797,0.755]$} & {$[0.797,0.755]$} & {$[0.515,0.542]$} \\
\hline $\mathrm{C} 15$ & {$[0.797,0.755]$} & {$[0.797,0.755]$} & {$[0.797,0.755]$} & {$[0.635,0.656]$} \\
\hline $\mathrm{C} 16$ & {$[0.597,0.614]$} & {$[0.597,0.614]$} & {$[0.597,0.614]$} & {$[0.597,0.614]$} \\
\hline $\mathrm{C} 17$ & {$[0.797,0.755]$} & {$[0.635,0.656]$} & {$[0.635,0.656]$} & {$[0.515,0.542]$} \\
\hline $\mathrm{C} 18$ & {$[0.658,0.678]$} & {$[0.658,0.678]$} & {$[0.658,0.678]$} & {$[0.658,0.678]$} \\
\hline $\mathrm{C} 19$ & {$[0.597,0.614]$} & {$[0.597,0.614]$} & {$[0.597,0.614]$} & {$[0.597,0.614]$} \\
\hline $\mathrm{C} 20$ & {$[0.369,0.408]$} & {$[0.424,0.436]$} & {$[0.354,0.395]$} & {$[0.490,0.534]$} \\
\hline $\mathrm{C} 21$ & {$[0.536,0.569]$} & {$[0.536,0.569]$} & {$[0.536,0.569]$} & {$[0.536,0.569]$} \\
\hline $\mathrm{C} 22$ & {$[0.597,0.614]$} & {$[0.597,0.614]$} & {$[0.597,0.614]$} & {$[0.597,0.614]$} \\
\hline $\mathrm{C} 23$ & {$[0.621,0.658]$} & {$[0.621,0.658]$} & {$[0.621,0.658]$} & {$[0.621,0.658]$} \\
\hline $\mathrm{C} 24$ & {$[0.621,0.658]$} & {$[0.621,0.658]$} & {$[0.621,0.658]$} & {$[0.621,0.658]$} \\
\hline $\mathrm{C} 25$ & {$[0.490,0.534]$} & {$[0.490,0.534]$} & {$[0.490,0.534]$} & {$[0.490,0.534]$} \\
\hline $\mathrm{C} 26$ & {$[0.515,0.523]$} & {$[0.515,0.523]$} & {$[0.515,0.523]$} & {$[0.515,0.523]$} \\
\hline $\mathrm{C} 27$ & {$[0.515,0.523]$} & {$[0.515,0.523]$} & {$[0.515,0.523]$} & {$[0.515,0.523]$} \\
\hline $\mathrm{C} 28$ & {$[0.536,0.569]$} & {$[0.536,0.569]$} & {$[0.536,0.569]$} & {$[0.536,0.569]$} \\
\hline $\mathrm{C} 29$ & {$[0.597,0.614]$} & {$[0.597,0.614]$} & {$[0.597,0.614]$} & {$[0.597,0.614]$} \\
\hline $\mathrm{C} 30$ & {$[0.515,0.542]$} & {$[0.515,0.542]$} & {$[0.515,0.542]$} & {$[0.797,0.755]$} \\
\hline C31 & {$[0.536,0.569]$} & {$[0.536,0.569]$} & {$[0.536,0.569]$} & {$[0.536,0.569]$} \\
\hline $\mathrm{C} 32$ & {$[0.597,0.614]$} & {$[0.597,0.614]$} & {$[0.597,0.614]$} & {$[0.597,0.614]$} \\
\hline $\mathrm{C} 33$ & {$[0.446,0.491]$} & {$[0.446,0.491]$} & {$[0.446,0.491]$} & {$[0.446,0.491]$} \\
\hline $\mathrm{C} 34$ & {$[0.797,0.755]$} & {$[0.797,0.755]$} & {$[0.797,0.755]$} & {$[0.797,0.755]$} \\
\hline $\mathrm{C} 35$ & {$[0.635,0.656]$} & {$[0.635,0.656]$} & {$[0.797,0.755]$} & {$[0.378,0.416]$} \\
\hline
\end{tabular}

Now, the grey rational grade is determined by Eq. (7). The weights of criteria are found by using Eq. (8). Table 6 shows the results.

\section{Table 6}

Criteria Weights

\begin{tabular}{lccc}
\hline Criteria & Weight & Criteria & Weight \\
\hline C1 & 0.023547053 & C19 & 0.028977044 \\
C2 & 0.022417828 & C20 & 0.020385398 \\
C3 & 0.031950765 & C21 & 0.026443132 \\
C4 & 0.020385398 & C22 & 0.028977044 \\
C5 & 0.023547053 & C23 & 0.030608077 \\
C6 & 0.025646593 & C24 & 0.030608077 \\
C7 & 0.047839783 & C25 & 0.02450304 \\
C8 & 0.028977044 & $\mathrm{C} 26$ & 0.024828452 \\
C9 & 0.031950765 & $\mathrm{C} 27$ & 0.024828452 \\
C10 & C28 & 0.026443132 \\
C11 & C29 & 0.028977044 \\
C12 & 0.031038669 & $\mathrm{C} 30$ & 0.028246015 \\
C13 & 0.024828452 & $\mathrm{C} 31$ & 0.026443132 \\
C14 & 0.028977044 & $\mathrm{C} 32$ & 0.028977044 \\
C15 & 0.028977044 & $\mathrm{C} 33$ & 0.022417828 \\
C16 & 0.034157055 & $\mathrm{C} 34$ & 0.037112575 \\
C17 & 0.035553382 & $\mathrm{C} 35$ & 0.029464101 \\
C18 & 0.028977044 & & \\
\hline
\end{tabular}


Eq. (9) is used to derive the likelihood matrix, as provided in Eq. (10). Finally, the ranking scores are determined for each alternative according to Eq. (11). Table 7 shows the results for final ranking scores of alternatives.

\section{Table 7}

Final Ranking for Alternatives

\begin{tabular}{lll}
\hline Alternatives & Final Score & Final Ranking \\
\hline Variant path1 & 0.310429037 & 2 \\
Variant path2 & 0.233853799 & 3 \\
Variant path3 & 0.324441406 & 1 \\
Variant path4 & 0.131275759 & 4 \\
\hline
\end{tabular}

Given the final scores obtained for the alternatives, Route 3 is defined as the best possible alternative.

As seen in Table 6, Criteria of C7, C34, C15 and C14 are more important than others, which represent the road longevity, views of NGO, route integration, and access to the route, respectively. Based on the decision table (see Table 3), the descriptions given for Route 3 as the best possible alternative indicates that it can be distinguished from other candidates in transportation and economic costs; and also, that less capital investment is needed for its development and construction. When constructed, total time spent traveling at this route would be more adequate, and it will be also possible to get the opponents to agree upon the construction of this route variant effectively and easily.

\section{Conclusion}

Because of high costs of roads/freeways construction and maintenance, decision making techniques play a great role in the design process of optimal variant routes. Iran with a wide range of intercity roads and freeways requires a framework for making appropriate choices in road and civil engineering construction projects. This paper aimed to develop a route choice model using MADM methods. To this end, the research process covered five main stages, starting with the attribute extraction for freeway variant routes using literature review and expert panel discussions. The process concluded with weighting and determining the most adequate variant route among a set of four alternatives for IsfahanShiraz freeway. As an integration of GRA and interval-valued dynamic intuitionistic fuzzy method, the proposed MADM approach was applied for deriving weights and priorities of alternatives.

The results obtained show that the criteria of road longevity, views of NGOs, route integration, and access to the route are identified as the highest-weighted criteria in variant prioritization. Ultimately, according to the alternatives prioritization, Route 3 was the optimal variant for Isfahan - Shiraz freeway. Routes 1, 2 and 4 were placed into the next lower ranks, respectively. Future studies are suggested to use hybrid MADM - GIS methods. In addition, expert-based techniques such as SWARA and DEMATEL can be utilized to weight particular criteria. In order to lower uncertainty, possible quantitative data may be applied for the evaluation of alternatives.

\section{References}

Abdi, E., Majnounian, B., Darvishsefat, A., Mashayekhi, Z., \& Sessions, J. (2009). A GIS-MCE based model for forest road planning. Journal of Forest Science, 55(4), 171-176.

Atkinson, D. M., Deadman, P., Dudycha, D., \& Traynor, S. (2005). Multi-criteria evaluation and least cost path analysis for an arctic all-weather road. Applied Geography, 25(4), 287-307.

Beljatynskij, A., Kuzhel, N., Prentkovskis, O., Bakulich, O., \& Klimenko, I. (2009). The criteria describing the need for highway reconstruction based on the theory of traffic flows and repay time. Transport, 24(4), 308317.

Brauers, W. K., Zavadskas, E. K., Peldschus, F., \& Turskis, Z. (2008a). Multi-objective decision-making for road design. Transport, 23(3), 183-193.

Brauers, W. K., Zavadskas, E. K., Peldschus, F., \& Turskis, Z. (2008b). Multi-objective optimization of road design alternatives with an application of the MOORA method. 
Cantarella, G. E., \& Vitetta, A. (2006). The multi-criteria road network design problem in an urban area. Transportation, 33(6), 567-588.

De Luca, M., Dell'Acqua, G., \& Lamberti, R. (2012). High-speed rail track design using GIS and multi-criteria analysis. Procedia-Social and Behavioral Sciences, 54, 608-617.

de Silva, H., \& Tatam, C. (1996). An empirical procedure for enhancing the impact of road investments. Transport policy, 3(4), 201-211.

Gardziejczyk, W., \& Zabicki, P. (2014). The influence of the scenario and assessment method on the choice of road alignment variants. Transport Policy, 36, 294-305.

Geneletti, D. (2005). Multicriteria analysis to compare the impact of alternative road corridors: a case study in northern Italy. Impact Assessment and Project Appraisal, 23(2), 135-146.

Gühnemann, A., Laird, J. J., \& Pearman, A. D. (2012). Combining cost-benefit and multi-criteria analysis to prioritise a national road infrastructure programme. Transport Policy, 23, 15-24.

Guzolek, J., \& Koch, E. (1989). Real-time route planning in road networks. Conference Record in Vehicle Navigation and Information Systems Conference.

Haghighat, F. (2011). Application of a multi-criteria approach to road safety evaluation in the Bushehr Province, Iran. PROMET-Traffic\&Transportation, 23(5), 341-352.

Jato-Espino, D., Castillo-Lopez, E., Rodriguez-Hernandez, J., \& Canteras-Jordana, J. C. (2014). A review of application of multi-criteria decision making methods in construction. Automation in Construction, 45, 151162.

Kalamaras, G. S., Brino, L., Carrieri, G., Pline, C., \& Grasso, P. (2000). Application of multicriteria analysis to select the best highway alignment. Tunnelling and Underground Space Technology, 15(4), 415-420.

Kuo, Y., Yang, T., \& Huang, G. W. (2008). The use of grey relational analysis in solving multiple attribute decision-making problems. Computers \& Industrial Engineering, 55(1), 80-93.

Lee, W., \& Lin, Y. (2011). Evaluating and ranking energy performance of office buildings using Grey relational analysis. Energy 36.

Li, D. F., Wang, Y. C., Liu, S., \& Shan, F. (2009). Fractional programming methodology for multi-attribute group decision-making using IFS. Applied Soft Computing, 9(1), 219-225.

Nosal, K., \& Solecka, K. (2014). Application of AHP method for multi-criteria evaluation of variants of the integration of urban public transport. Transportation Research Procedia, 3, 269-278.

Price, A. (1999). The new approach to the appraisal of road projects in England. Journal of transport economics and policy, 33(2), 221-226.

Russo, F., \& Vitetta, A. (2006). A topological method to choose optimal solutions after solving the multi-criteria urban road network design problem. Transportatio, 33(4), 347-370.

Saaty, T. L. (1988). What is the analytic hierarchy process?. In Mathematical models for decision support (pp. 109-121). Springer, Berlin, Heidelberg.

Wang, P., Meng, P., Zhai, J. Y., \& Zhu, Z. Q. (2013). A hybrid method using experiment design and grey relational analysis for multiple criteria decision making problems. Knowledge-Based Systems, 53, 100-107.

Wei, G. W. (2010). GRA method for multiple attribute decision making with incomplete weight information in intuitionistic fuzzy setting. Knowledge-Based Systems 23.3, 23(3), 243-247.

Xiaowei, L. (2013). Decision-making Method of Highway Network Planning based on Prospect Theory. Procedia-Social and Behavioral Sciences, 96.

Yakar, F., \& Celik, F. (2014). A highway alignment determination model incorporating GIS and Multi-Criteria Decision Making. KSCE Journal of Civil Engineering, 18(6), 1847-1857.

Yavuz, M., Iphar, M., \& Once, G. (2008). The optimum support design selection by using AHP method for the main haulage road in WLC Tuncbilek colliery. Tunnelling and Underground Space Technology, 23(2), 111119.

Zhang, Q. (2005). Road network generalization based on connection analysis. Developments in Spatial Data Handling Springer Berlin Heidelberg, 343-353.

Zhang, S. F., Liu, S. Y., \& Zhai, R. H. (2011). An extended GRA method for MCDM with interval-valued triangular fuzzy assessments and unknown weights. Computers \& Industrial Engineering, 61(4), 1336-1341.

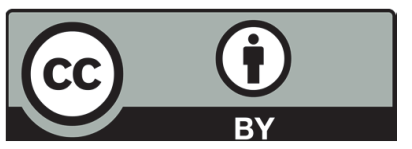

(C) 2018 by the authors; licensee Growing Science, Canada. This is an open access article distributed under the terms and conditions of the Creative Commons Attribution (CC-BY) license (http://creativecommons.org/licenses/by/4.0/). 